\title{
Insectos suicidas: irregularidades en su comportamiento
}

\author{
Daniel Ochoa-García y Reinier Núñez-Bazán
}

\section{Resumen}

El suicidio no es un comportamiento limitado a sólo los seres humanos, también los insectos suelen tener un comportamiento suicida similar. Sin embargo, en ellos está comúnmente ligado a algunas de sus necesidades, como la reproducción, la defensa y, en algunos casos muy puntuales, con el parasitismo. En este último este tema existe gran controversia debido a que los insectos actúan por instinto y por ello, en muchas ocasiones, no se considera como un suicidio per se. No obstante, el que estos animales actúen por instinto no descarta que, desde el punto de vista práctico, se pueda contemplar como tal.

Palabras clave: parásitos, autosacrificio, insectos eusociales, autolisis.

\section{SUICIDAL INSECTS: IRREGULARITIES IN THEIR BEHAVIOR}

\begin{abstract}
Suicide is not a behavior limited to human beings. Insects usually have a suicidal behavior similar to the one that occurs in some humans. Nevertheless, in insects are highly linked to needs such as reproduction, defense and in some specific cases parasitism. In this matter, there is great controversy because insects act by instinct and therefore on many cases it is not considered as suicide per se. However, that these animals act by instinct does not rule out that, from a practical point of view, we can consider this behavior as suicide.
\end{abstract}

Keywords: parasites, self-sacrifice, eusocial insects, autolysis.

Recepción: 17/08/2020. Aprobación: 17/02/2021. Dol: http://doi.org/10.22201/cuaieed.16076079e.2021.22.3.8 


\section{Daniel Ochoa-García}

ochoagarciadaniel@gmail.com

Egresado de la Universidad Autónoma de Chihuahua como Ingeniero en Ecología. Actualmente cursa sus estudios de posgrado en la Maestría en Biología Integrativa de la Biodiversidad y la Conservación (MBIBYc) en la Universidad Autónoma del Estado de Morelos. Realizó estancias de investigación en la Universidad Nacional Autónoma de México (UNAM), en la Colección Nacional de Mamíferos (2017) y en el Laboratorio de Interacciones y Procesos Ecológicos de la Facultad de Ciencias (2018), así como en el Centro Interdisciplinario de Investigación para el Desarrollo Integral Regional (CIIDIR)-Unidad Durango (2019). Sus líneas de investigación incluyen ecología de comunidades, el análisis de la diversidad y la conservación de insectos.

\section{Reinier Núñez-Bazán}

rnbazan7@gmail.com

orcid.org/0000-0002-8622-3373

Egresado de la Facultad de Biología, Universidad de La Habana, como Licenciado en Biología. Actualmente cursa sus estudios de posgrado en la Maestría en Biología Integrativa de la Biodiversidad y la Conservación (MBIBYc) en la Universidad Autónoma del Estado de Morelos. Fue profesor de Zoología de Cordados, Zoología de Invertebrados y Biología del Desarrollo en la carrera de Biología (Facultad de Biología, Universidad de La Habana) por dos años (2018-2020). Sus líneas de investigación incluyen la ecología poblacional y de comunidades, la diversidad y conservación de insectos, taxonomía de insectos y biogeografía. Sus estudios se centran en el orden blattodea, aunque también incursiona en otros grupos de Orthopteroides como Mantodea, Phasmatodea, Orthoptera y Dermaptera. 


\section{Introducción}

El comportamiento suicida es un proceso biopsicosocial, es decir, un proceso que integra cuestiones biológicas, psicológicas y sociales, sumamente complejo que atenta contra los instintos básicos de autopreservación de cualquier organismo. Por ende, constituye un verdadero reto para el estudio de los procesos complejos de comportamiento y de evolución. En sociedades humanas, es un tema de investigación central para muchos psicólogos, sin embargo, la abrumadora variabilidad de motivos y de medios del suicidio entre las sociedades, los estratos sociales y las culturas, lo convierte en un tema controversial y debatible. Pero el suicidio no se limita solamente a los seres humanos, existen varios ejemplos reportados de este comportamiento contrario a la autopreservación dentro del reino animal.

En insectos, los casos más conocidos se dan en poblaciones complejas de insectos eusociales ${ }^{1}$. En ocasiones se ha considerado que los humanos son el grupo de vertebrados ${ }^{2}$, con mayor similaridad a los grupos de insectos eusociales (Joiner, et al., 2016) pero, a pesar del parecido, la fijación evolutiva de este comportamiento autodestructivo difiere notablemente entre los insectos y los humanos. En insectos eusociales, se describe la presencia de comportamientos autodestructivos, pero siempre con el objetivo de la preservación del acervo genético ${ }^{3}$ compartido con sus congéneres ${ }^{4}$.

Un ejemplo de lo anterior son las abejas obreras, estas, generalmente, mueren después de picar y se cree que tal comportamiento de sacrificio tiene como objetivo aumentar las posibilidades de supervivencia en individuos reproductores que comparten los genes del individuo suicida (Wilson, 1971). No

${ }^{1}$ Poblaciones de insectos donde varias generaciones cooperan en el cuidado de las crías y generalmente tienen castas estériles y reproductoras.

2 animales con columna vertebral. ${ }^{3}$ Conjunto de variaciones presentes en el material genético de la totalidad de individuos de una población.

${ }^{4}$ Que pertenecen a una misma especie.

${ }^{5}$ los científicos que estudian a los insectos.

${ }^{6}$ los científicos que estudian la conducta animal.

${ }^{7}$ Insectos que poseen algún organismo parásito asociado a su cuerpo.

8 Parásitos que matan a su hospedero con el fin de completar su ciclo de vida. obstante, abundan los casos de insectos suicidas fuera de eusociedades.

Debido a la gran complejidad de este comportamiento, generalmente existen preguntas alrededor del tema, como: ¿Cuáles son los agentes causantes de este tipo de comportamiento en los insectos? o, ¿Qué relación guarda este comportamiento con su supervivencia y con su evolución? Estas son algunas cuestiones que trataremos de responder en el siguiente escrito y con ello brindaremos un acercamiento al conocimiento de este fenómeno que despierta el interés de los entomólogos ${ }^{5}$ y de los etólogos ${ }^{6}$.

\section{Insectos parasitados}

Uno de los ejemplos más interesantes del comportamientos autodestructivos en insectos quizás sea el de insectos parasitados ${ }^{7}$, ya que, en muchos casos, estos parásitos o parasitoides ${ }^{8}$ consiguen modificar el comportamiento del hospedero para así lograr algún objetivo y/o completar su ciclo de vida. Tal es el caso del parásito Spinochordodes tellinii, un gusano que, al entrar al cuerpo de algún insecto de suelo, principalmente saltamontes y grillos, segrega una batería de 
Imagen 1. Saltamontes parasitado por Spinochordodes tellinii (Dbenzhuser, 2016).
${ }^{9}$ Animales que se alimentan fundamentalmente de plantas. sustancias químicas en el individuo, que alteran el sistema nervioso del insecto, y provocan un raro comportamiento suicida que lo obliga a acercarse a cuerpos de agua y a saltar dentro de ellos. Este fenómeno culmina con la muerte del hospedero por asfixia y una vez en el agua, el parásito se apresura a salir de su recipiente para continuar su ciclo vital acuático (ver imagen 1).

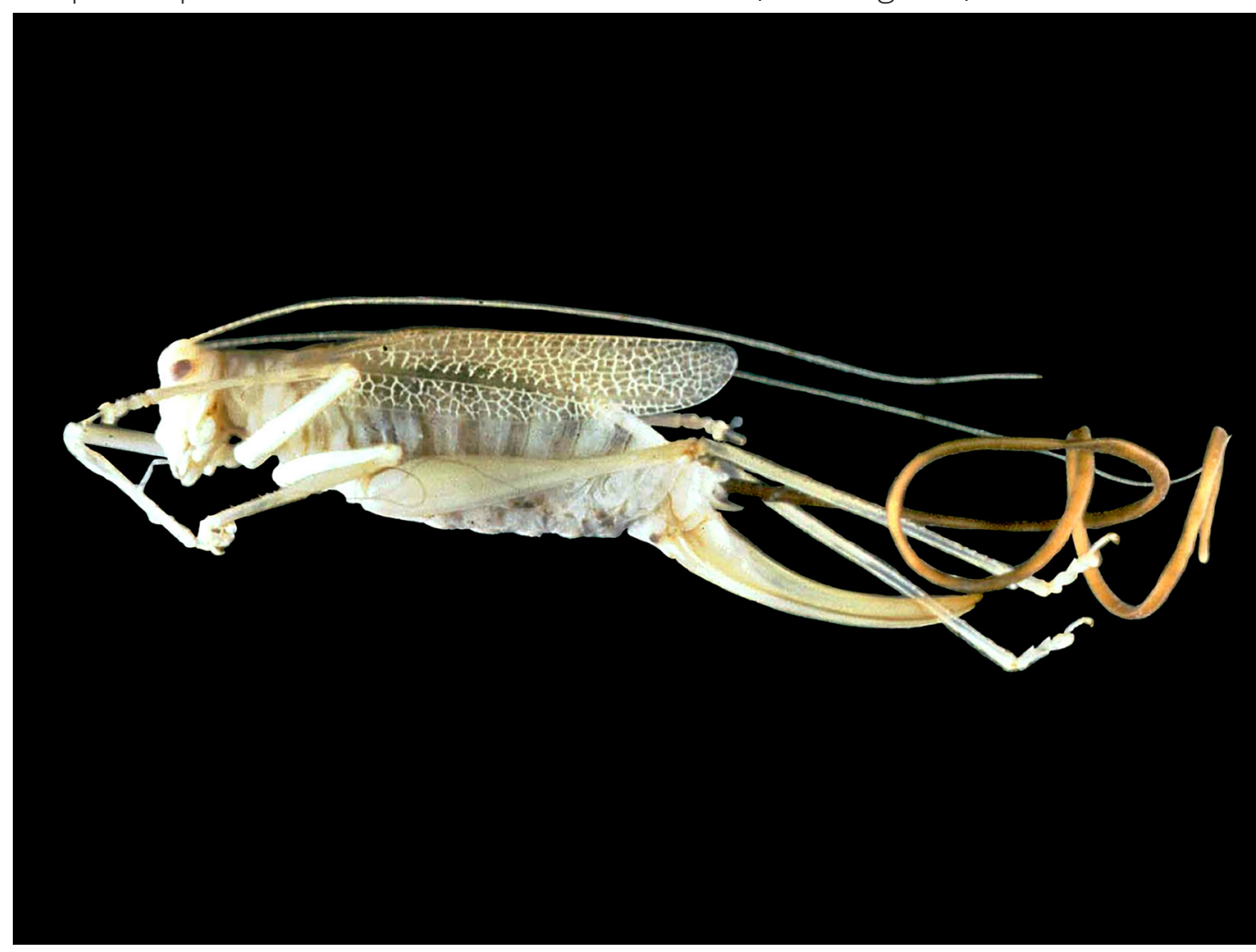

Este comportamiento fue observado por científicos franceses dirigidos por David G. Biron que observaron saltamontes ahogados en una piscina en el sur de Francia y afirmaron que, el gusano Spinochordodes tellinii provocó la muerte del insecto al estropear su sistema nervioso central y al logra manejar el comportamiento del saltamontes hasta provocarle la muerte (Biron et al., 2005).

Algunos parásitos tienen ciclos de vida complejos, pasan por varios hospederos hasta llegar a su receptor final. Este es el caso de la duela, Dicrocoelium dendriticum, parásita del hígado de animales herbívoros ${ }^{9}$, como las vacas y las ovejas. Las duelas maduras liberan sus huevos en las heces del hospedero, que luego serán comidas por caracoles, donde nacen las larvas para después ser expulsadas recubiertas de una capa viscosa proveniente del caracol. Estas bolas resultan atractivas para la hormiga, Formica fusca, y, en consecuencia, se las come (Hohorst y Graefe, 1961). Una vez dentro de ella, el parásito se mueve hacia el cerebro, donde libera químicos que modifican su comportamiento habitual.

Así que, al llegar la noche y al bajar la temperatura, la hormiga "zombificada" sale del nido y trepa hasta la punta de la hoja de una hierba, se aferra con las 
mandíbulas y espera su fatídico final, después, un herbívoro se la come junto al forraje, para completar así el ciclo de la duela. Si al llegar la mañana la hormiga no ha sido comida, esta vuelve a la colonia y continúa con sus actividades hasta el anochecer, cuando repetirá el mismo procedimiento, hasta lograr ser comida.

No sólo los animales parásitos son capaces de modificar el comportamiento de los insectos, existen otros organismos, como los hongos, que a pesar de su "simplicidad" poseen extraordinarias estrategias de vida. Por ejemplo, una hormiga puede ser manipulada por un hongo parásito del género Cordyceps, y al estar bajo su control cambia su comportamiento a uno que facilita la reproducción y la dispersión del hongo (Hughes, 2015) mediante la producción de químicos que alteran el sistema de navegación de la hormiga.

Todo comienza con la entrada al organismo hospedero de las esporas ${ }^{10}$ del hongo a través de su sistema respiratorio. Una vez dentro, el parásito crece, se alimenta de los tejidos no vitales y deja el sistema nervioso intacto. Una vez alcanzada su madurez, el hongo libera ciertos químicos que provocan cambios en la hormiga, la hacen trepar a la cima de un árbol o cualquier otra planta para fijarse a una hoja con sus mandíbulas. Una vez ahí, el hongo se alimenta de su cerebro, lo que provoca su crecimiento y su ramificación fuera del cuerpo de la hormiga mientras libera sus esporas que se alojarán en el cuerpo de un nuevo hospedero, reanudado el ciclo. En este caso, la hormiga parasitada muere por la destrucción interna de su organismo, o si el proceso demora, fallece de inanición por el tiempo prolongado que estuvo obligada a fijarse a un sustrato vegetal (ver imagen 2).

Imagen 2. Hormiga Camponotus leonardi parasitada por el hongo Ophiocordyceps unilateralis (Pontoppidan, Himaman, HywelJones, Boomsma y Hughes, 2009).

${ }^{10}$ Cuerpo microscópico conformado por una o varias células que puede dar lugar a un nuevo individuo. Es utilizado como medio de reproducción en algunos organismos como los hongos.

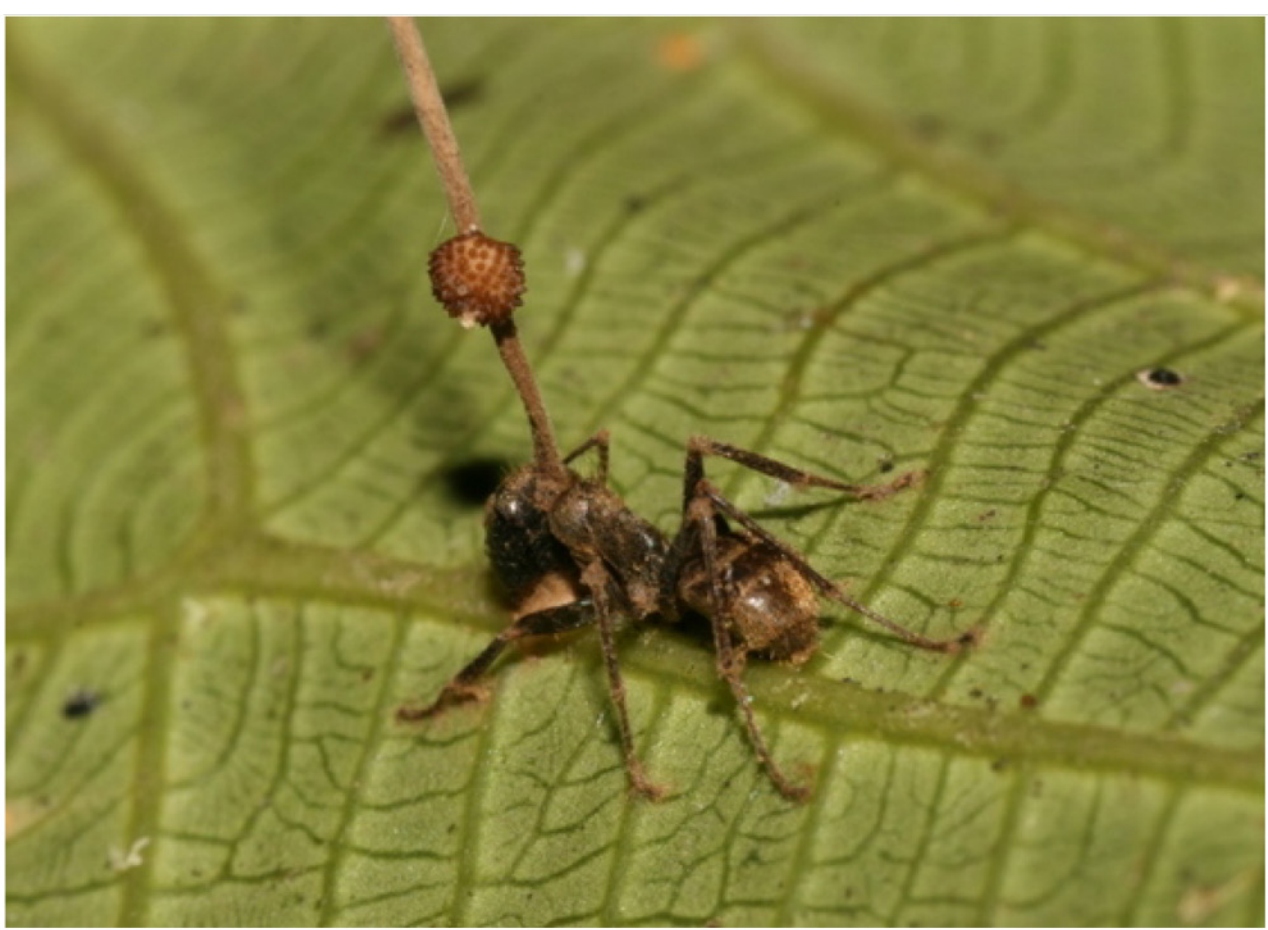




\section{Reproducción suicida}

En la naturaleza son muchos los ejemplos de animales que con tal de asegurar su éxito reproductivo o su supervivencia de su prole, pueden llegar a realizar comportamientos autodestructivos o suicidas. Un ejemplo de este fenómeno son los eventos reproductivos de algunas especies de insectos. Ciertos animales viajan cientos de kilómetros para reproducirse y morir, otros entran en un frenesí reproductivo luego de alcanzar la madurez, sin permitirse un tiempo para comer, lo cual les provoca la muerte. A estos y a otros tipos de comportamientos que terminan con la vida del animal y que están relacionados de alguna manera con la reproducción, es a lo que llamaremos "reproducción suicida" en este escrito.

Quizá el evento de reproducción suicida más conocido es el presente en la reproducción de algunas especies de mantis. Tomaremos por ejemplo a Stagmomantis limbata, esta especie de mántido presenta un comportamiento nupcial peculiar por parte de los machos. Si este detecta la posibilidad de aparearse con más de una hembra disminuye al mínimo la posibilidad de ser canibalizado. Sin embargo, en condiciones controladas, se ha observado un comportamiento suicida cuando no existe posibilidad de volver a aparearse (Maxwell, 1998). Posiblemente, la evolución llevó a que los machos de esta especie desarrollen dos tipos de comportamientos durante el cortejo y la reproducción: la primera, la autopreservación para asegurarse de dejar un mayor número de descendencia, y la segunda, el suicidio, que constituye un regalo nupcial, para asegurar el desarrollo de crías fuertes al darle su cuerpo a la hembra como comida justo cuando comienza la formación de sus huevos.

Imagen 3. Cyphoderris strepitans al momento de succionar la hemolinfa del macho durante la cópula (Judge, 2009).

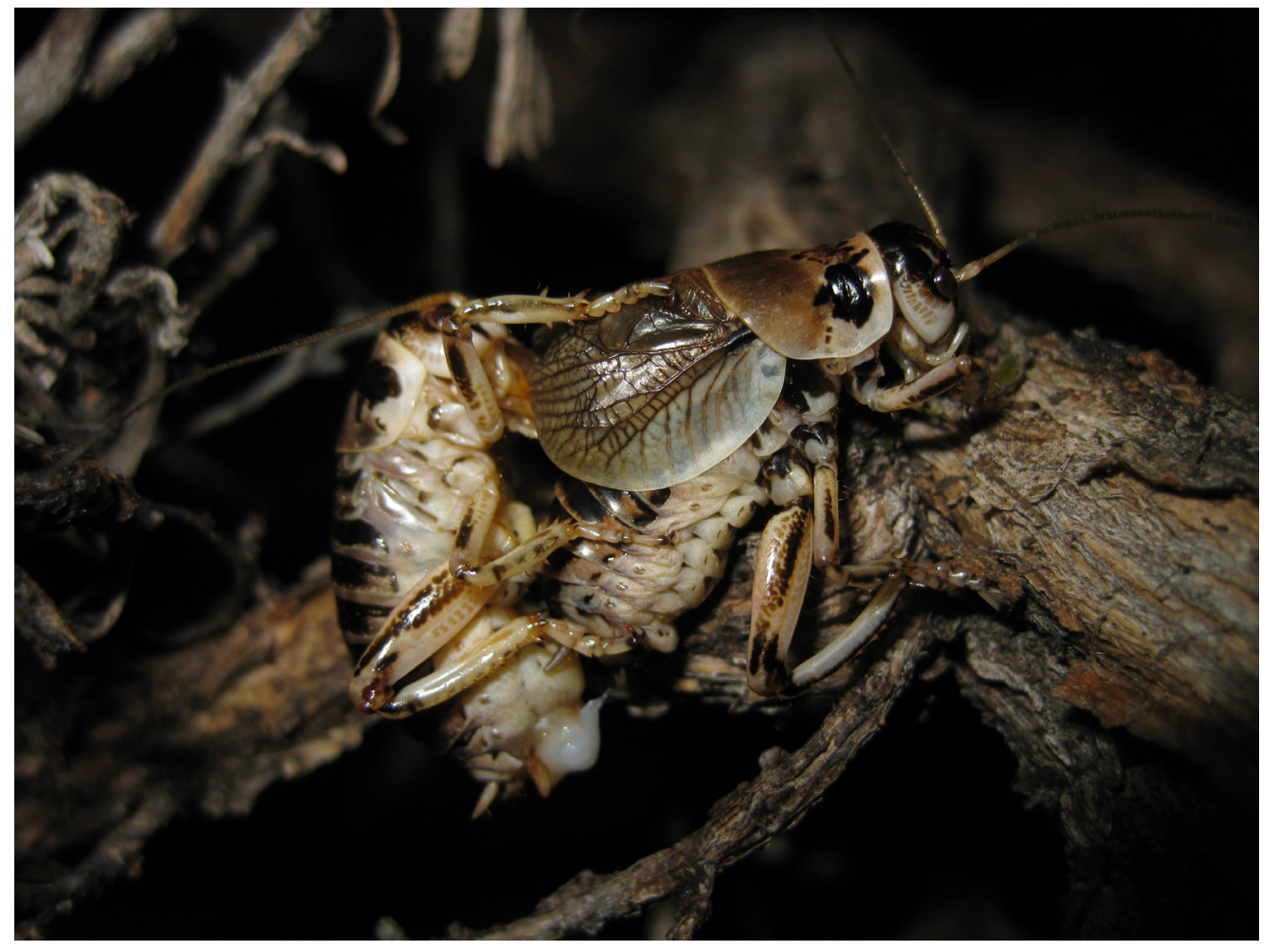


Otro caso no tan conocido, pero sin duda muy interesante, es el de la especie Cyphoderris strepitans (imagen 3), un grillo distribuido exclusivamente en las montañas de Colorado y Wyoming en Estados Unidos, este comportamiento se basa en que la hembra se alimenta de las alas posteriores del macho durante la cópula y consume la hemolinfa ${ }^{11}$ que fluye de las heridas infligidas (Eggert y Sakaluk, 1994). Como en el ejemplo anterior, aquí el macho asegura una comida nutritiva para su pareja, y así garantiza la formación de los huevos que llevan sus genes. En este tipo de canibalismo sexual, los machos sin duda saben que van hacia la muerte, y toman esa actitud de "suicidio" con el único fin de lograr transferir sus genes a generaciones futuras, con éxito.

\section{Sacrificio propio por el bien común}

Las abejas son unos de los insectos más populares, y presentan una de las estrategias defensivas más conocidas. A la mayoría de las personas las ha picado una, y todo aquel que haya pasado por esa situación sabe que tras la picadura, hay un aguijón. Precisamente, por esta razón, las abejas encabezan este acápite, donde ciertos insectos eusociales son capaces de sacrificarse para proteger la integridad del resto.

Las abejas tienen un comportamiento defensor característico que podría considerarse un suicidio: al momento de insertar su aguijón, las glándulas asociadas con este se desprenden junto a su abdomen, lo que provoca, inevitablemente, la muerte del individuo. Cabe resaltar que no todas las abejas mueren en cuestión de pocas horas, algunas sobreviven durante unos días más (Hydak, 1951) y continúan con sus actividades en sus colmenas, solo que en lugar de picar, muerden o acosan al potencial intruso de la colonia. Algo muy interesante es que, a diferencia de los otros ejemplos, estas abejas que pican y mueren, no se reproducen. Así, este instinto básico que las lleva a realizar el sacrificio está fundamentado por la supervivencia del grupo, donde sí hay individuos reproductores que portan sus mismos genes.

Otro sacrificio muy utilizado en la naturaleza es la autólisis, esto se refiere a la ruptura espontánea, interna y fatal de un bolso que libera una sustancia nociva. Este mecanismo evolucionó, principalmente para el combate con otros insectos que representen una amenaza para la comunidad (Shorter y Rueppell, 2012). Un ejemplo muy interesante es el de la hormiga Colobopsis saundersi (ver imagen 4), esta especie se distribuye en el sudeste asiático y tienen una peculiar conducta durante la defensa de su hormiguero al ser atacado por algún agresor: las hormigas se lanzan sobre la amenaza, se adhieren fuertemente a

${ }^{11}$ Líquido circulatorio de algunos invertebrados, análogo de la sangre en vertebrados. él y explotan para impregnarlo del veneno cuidadosamente guardado en su interior, ambos individuos suelen morir en el acto, el invasor envenenado y la hormiga al explotar (Jones et al. 2004). 
Imagen 4. Colobopsis saundersi explotan cuando realizan un combate con un agresor

(Tawatao, 2009).

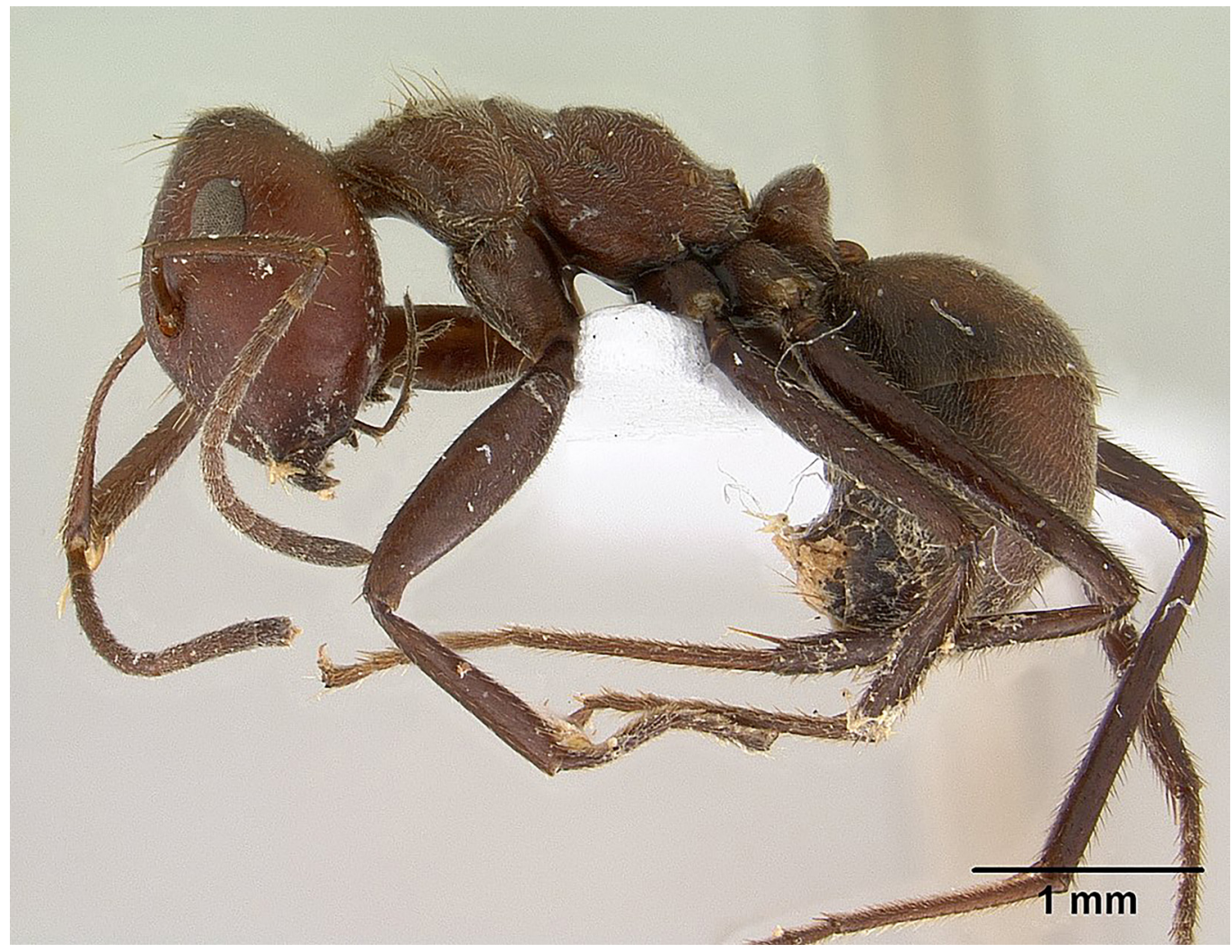

Conclusión

El suicidio en animales suscita una fuerte controversia entre los etólogos y los psicólogos; sin embargo, varios son los casos de estudio demuestran la presencia de este comportamiento tan contradictorio en varias especies no humanas. El principal alegato de aquellos negados a la existencia del suicidio en animales está fundamentado en la ausencia de premeditación, ya que estos animales actúan por instinto. Pero no se puede descartar que, desde el punto de vista práctico, guiados o no por instinto, estos animales se suicidan. En insectos es un tema recurrente, tanto que hay literatura plagada de ejemplos muy interesantes. Aun así, queda mucho por conocer acerca de este fenómeno en los animales, y en especial, en los insectos, pero la ciencia y el interés por comprender el funcionamiento de los sistemas vivos lentamente avanza en esta dirección.

Sin duda alguna, el termino suicidio, está muy ligado a la visión antropocentrista del hombre, pero ya son varios los casos en animales que perfectamente pueden ser agrupados bajo este término. La naturaleza es compleja y por ende, su total entendimiento. 


\section{Referencias}

Biron, D. G., Marché, L., Ponton, F., Loxdale, H. D., Galéotti, N., Renault, L. y Thomas, F. (2005). Behavioural manipulation in a grasshopper harbouring hairworm: a proteomics approach. Proceedings of the Royal Society B: Biological Sciences, 272(1577), 2117-2126. https://doi.org/10.1098/rspb.2005.3213

* Dbenzhuser. (2016, 14 de agosto). Spinochordodes in Meconema. https:// commons.wikimedia.org/wiki/File:Spinochordodes_in_Meconema.jpg

* Eggert, A. K., y Sakaluk, S. K. (1994). Sexual cannibalism and its relation to male mating success in sagebrush crickets, Cyphoderris strepitans (Haglidae: Orthoptera). Animal Behaviour, 47,(5) 1171-1177. https://doi.org/10.1006/ anbe.1994.1155

* Haydak, M. H. (1951). How long does a bee live after losing its sting? Glean. Bee cult, 79, 85-86.

- Hohorst, W., y Graefe, G. (1961). Ameisen-obligatorische Zwischenwirte des Lanzettegels (Dicrocoelium dendriticum). Naturwissenschaften, 48, 229-230. https://doi.org/10.1007/BF00597502

Hughes, D. P. (2015). Behavioral ecology: manipulative mutualism. Current Biology, 25(18), 806-808. https://doi.org/10.1016/j.cub.2015.07.067

* Joiner, T. E., Hom, M. A., Hagan, C. R., y Silva, C. (2016). Suicide as a derangement of the self-sacrificial aspect of eusociality. Psychological Review 123(3), 235-254. https://doi.org/10.1037/rev0000020

* Jones, T.H., Clark, D.A., Edwards, A.A., Davidson, D.W., Spande, T.F. y Snelling, R. R. (2004). The Chemistry of Exploding Ants, Camponotus spp. (Cylindricus COMPLEX). Journal of Chemical Ecology, 30, 1479-1492. https://doi.org/10.1023/ b:joec.0000042063.01424.28

* Judge, K. [kjudge]. (2009, 16 de junio). Foto 12280736 [Cyphoderris strepitans]. https://www.naturalista.mx/photos/12280736

* Maxwell, M. R. (1998). Lifetime mating opportunities and male mating behaviour in sexually cannibalistic praying mantids. Animal Behaviour, 55(4), 1011-1028. https:// doi.org/10.1006/anbe.1997.0671

* Pontoppidan, M. B., Himaman, W., Hywel-Jones, N. L., Boomsma, J. J., Hughes, D. P. (2009). Graveyards on the Move: The Spatio-Temporal Distribution of Dead Ophiocordyceps-Infected Ants. PLOS ONE, 4(3), e4835. https://doi.org/10.1371/ journal.pone.0004835

- Shorter, J. R., y Rueppell, O. (2012). A review on self-destructive defense behaviors in social insects. Insectes Sociaux, 59, 1-10. https://doi.org/10.1007/s00040-011-0210-x

- Tawatao, N. (2009, 12 de junio). Camponotus saundersi casent0179025 profile 1 [fotografía]. https://cutt.ly/jcHIWf]

* Wilson, E. O. (1971). The insect societies. Harvard University Press. 


\section{Agradecimientos}

A David Corral García por sus comentarios y revisión del abstract.

\section{Cómo citar este artículo}

* Ochoa-García, Daniel y Núñez-Bazán, Reinier. (2021, mayo-junio). Insectos suicidas: irregularidades en su comportamiento. Revista Digital Universitaria (RDU), 22(3). http://doi.org/10.22201/cuaieed.16076079e.2021.22.3.8 